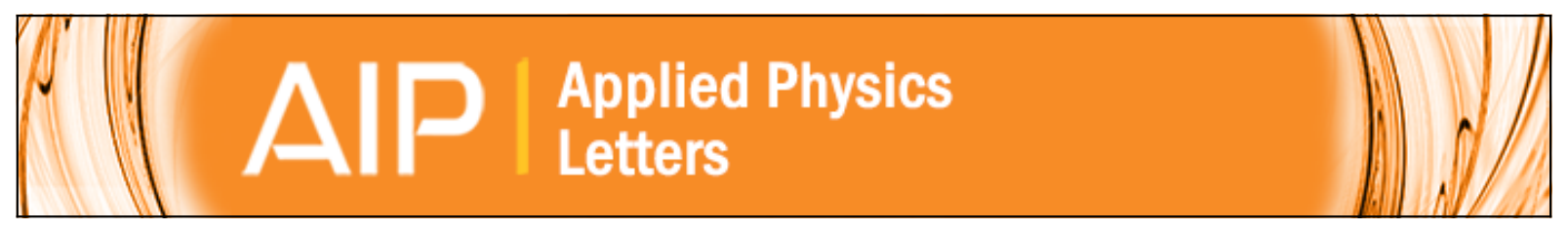

\title{
Enhancement of magnetic properties by nitrogen implantation to Mn-implanted p-type GaN
}

Jeong Min Baik, Yoon Shon, Tae Won Kang, and Jong-Lam Lee

Citation: Applied Physics Letters 84, 1120 (2004); doi: 10.1063/1.1647282

View online: http://dx.doi.org/10.1063/1.1647282

View Table of Contents: http://scitation.aip.org/content/aip/journal/apl/84/7?ver=pdfcov

Published by the AIP Publishing

\section{Articles you may be interested in}

Enhancement of the magnetic properties in ( $\mathrm{Ga} 1-\mathrm{x} \mathrm{Mnx}$ ) $\mathrm{N}$ thin films due to Mn-delta doping

Appl. Phys. Lett. 87, 092501 (2005); 10.1063/1.2032587

Room temperature ferromagnetism in cubic $\mathrm{GaN}$ epilayers implanted with $\mathrm{Mn}+$ ions

Appl. Phys. Lett. 85, 3777 (2004); 10.1063/1.1812590

Microstructural, optical, and magnetic properties of Mn-implanted p-type GaN

J. Appl. Phys. 93, 9024 (2003); 10.1063/1.1572974

Effect of microstructural change on magnetic property of Mn-implanted p-type GaN

Appl. Phys. Lett. 82, 583 (2003); 10.1063/1.1541111

Magnetic and structural properties of Mn-implanted GaN

Appl. Phys. Lett. 78, 3475 (2001); 10.1063/1.1376659

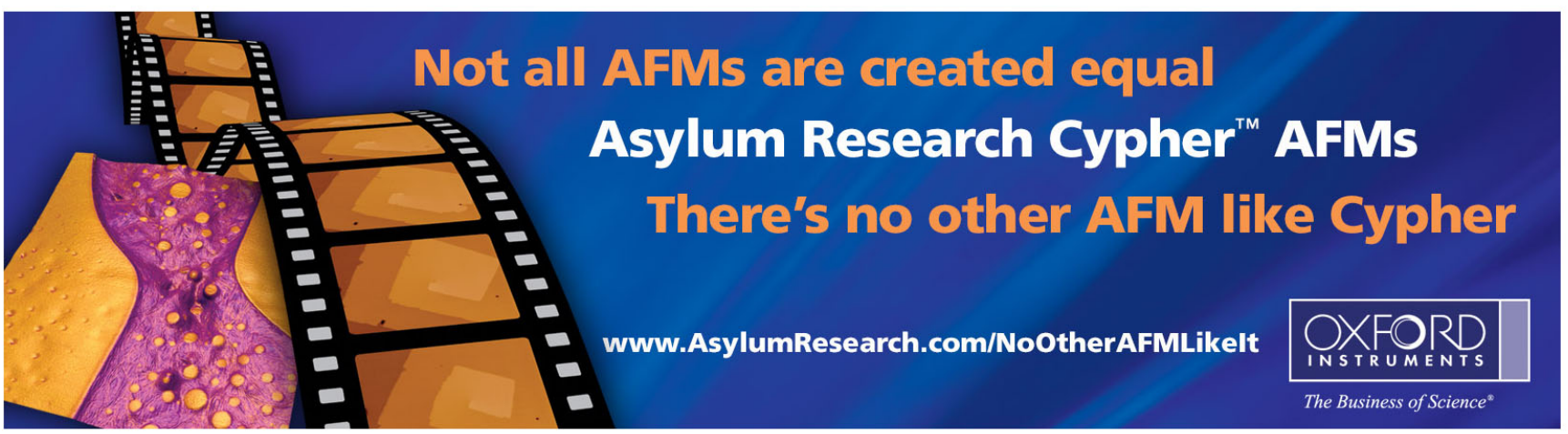




\title{
Enhancement of magnetic properties by nitrogen implantation to Mn-implanted $p$-type GaN
}

\author{
Jeong Min Baik \\ Department of Materials Science and Engineering, Pohang University of Science and Technology \\ (POSTECH), Pohang, Kyungbuk 790-784, Korea \\ Yoon Shon and Tae Won Kang \\ Quantum Functional Semiconductor Research Center, Dongguk University, 3-26 Pil-dong, Chung-ku, \\ Seoul 100-715, Korea \\ Jong-Lam Lee ${ }^{\text {a) }}$ \\ Department of Materials Science and Engineering, Pohang University of Science and Technology \\ (POSTECH), Pohang, Kyungbuk 790-784, Korea
}

(Received 27 August 2003; accepted 18 December 2003)

$\mathrm{N}$ and $\mathrm{Mn}$ ions were co-implanted into $p$-type $\mathrm{GaN}$ and subsequently annealed at $700-900{ }^{\circ} \mathrm{C}$. Compared with Mn-implanted sample, the $(\mathrm{Mn}+\mathrm{N})$-implanted sample revealed a larger ferromagnetic signal. This was attributed to the increase of $\mathrm{Ga}-\mathrm{Mn}$ magnetic phases. $\mathrm{Mn}-\mathrm{N}$ compounds, such as $\mathrm{Mn}_{6} \mathrm{~N}_{2.58}$ and $\mathrm{Mn}_{3} \mathrm{~N}_{2}$, decreased and the resistivity significantly increased, meaning a reduction of $\mathrm{N}$ vacancies. It is suggested that enhancement in ferromagnetic properties in the $(\mathrm{Mn}+\mathrm{N})$-implanted $\mathrm{GaN}$ originated from the reduction of $\mathrm{N}$ vacancies and the increase of Ga-Mn magnetic phases. (C) 2004 American Institute of Physics. [DOI: 10.1063/1.1647282]

Diluted magnetic semiconductors (DMSs) based on III-V semiconductors, such as GaAs and GaN, can be fabricated by incorporating a high concentration of magnetic ions into III-V semiconductors by molecular-beam epitaxy (MBE) or ion implantation. ${ }^{1-5}$ In particular, it was theoretically suggested that $(\mathrm{Ga}, \mathrm{Mn}) \mathrm{N}$ films with a high $\mathrm{Mn}$ concentration $(\sim 5$ at. $\%)$ and a high hole concentration $\left(\sim 10^{20} \mathrm{~cm}^{-3}\right)$ could yield a high $T_{c}(\geqslant 300 \mathrm{~K}){ }^{6}$ This allows spintronic devices to operate at room temperature. Recently, Mn-doped GaN films showing ferromagnetic behavior above room temperature were grown on sapphire (0001) by MBE. ${ }^{5}$ The ferromagnetic property was also reported in Mn-implanted GaN with subsequent annealing. ${ }^{4}$ However, some phases could be formed in the films due to the low solubility of magnetic ions in $\mathrm{GaN}$, such as ferromagnetic $\mathrm{Ga}-\mathrm{Mn}$ and ferrimagnetic $\mathrm{Mn}-\mathrm{N}$ compounds. These precipitates could give a major contribution to the total magnetic moment of the samples. However, the effects of such compounds on magnetic properties were not clear. It was suggested that several $\mathrm{Mn}-\mathrm{N}$ compounds were responsible for the ferromagnetic behavior of $(\mathrm{Ga}, \mathrm{Mn}) \mathrm{N} \mathrm{films.}{ }^{7}$ On the other hand, there were also reports that ferromagnetic properties were attributed to the formation of $\mathrm{Ga}-\mathrm{Mn}$ compounds. ${ }^{4,8}$ The origin of ferromagnetic properties in GaN-based DMSs is still unclear.

In this work, we investigated microstructural evolutions of $\mathrm{Mn}$ - and $(\mathrm{Mn}+\mathrm{N})$-implanted $p$-type $\mathrm{GaN}$ as a function of annealing temperature. Synchrotron $\mathrm{x}$-ray diffraction (XRD) and synchrotron radiation photoemission spectroscopy (SRPES) were employed to identify secondary phases and chemical bonding states in the samples. From these, the effects of implanted $\mathrm{N}$ ions on magnetic properties in $\mathrm{Mn}$ implanted GaN are discussed.

${ }^{a)}$ Electronic mail: jllee@postech.ac.kr
The GaN films were grown by metalorganic chemicalvapor deposition on a (0001) sapphire substrate. An undoped $\mathrm{GaN}$ layer with a thickness of $1 \mu \mathrm{m}$ was grown, followed by the growth of $1-\mu \mathrm{m}$-thick $p$-type $\mathrm{GaN}$ doped with $\mathrm{Mg}$. Electrical activation of the grown samples was carried out at $750^{\circ} \mathrm{C}$ for 4 min by rapid thermal annealing (RTA) under a $\mathrm{N}_{2}$ atmosphere. Hall measurements determined that the net hole concentration in the film was $2.5 \times 10^{17} \mathrm{~cm}^{-3}$.

First, the $\mathrm{N}+$ ions were implanted at $35 \mathrm{keV}$ to position the ion peak $80 \mathrm{~nm}$ from the surface. The $\mathrm{Mn}+$ ions were then implanted at $180 \mathrm{keV}$ to place its peak range at the same position as that of the $\mathrm{N}+$ ions. Both $\mathrm{N}$ and $\mathrm{Mn}$ implant dosages were $5 \times 10^{16} \mathrm{~cm}^{-2}$. For reference, GaN samples implanted with only $\mathrm{Mn}^{+}$ions were also prepared. All samples were held at $350{ }^{\circ} \mathrm{C}$ during the implantation to avoid amorphization. Subsequent annealing at $700-900{ }^{\circ} \mathrm{C}$ for $30 \mathrm{~s}$ was performed under a flowing $\mathrm{N}_{2}$ gas in a face-to-face condition. Magnetization measurement was carried out using a superconducting quantum interference device magnetometer (MPMSXL, Quantum Design Co., Ltd.). For resistivity measurement, the samples were patterned using the transmission line method with $100 \times 50 \mu \mathrm{m}^{2}$ pads. Ti/Al/Ni/Au (300/ $1200 / 400 / 500 \AA$ ) contact was annealed under a $\mathrm{N}_{2}$ atmosphere at $500^{\circ} \mathrm{C}$ for 1 min using RTA.

Figure 1 shows magnetization curves at $10 \mathrm{~K}$ for the Mn-implanted and $(\mathrm{Mn}+\mathrm{N})$-implanted samples annealed at $800^{\circ} \mathrm{C}$. The magnetization curves were obtained with the applied field parallel to the plane of the samples. The diamagnetic background of GaN substrate was subtracted. The hysteresis loops of both samples showed clear ferromagnetic behavior. The ferromagnetic signal for the $(\mathrm{Mn}+\mathrm{N})$ implanted sample was stronger than that of the Mnimplanted one. The coercive field $\left(H_{C}\right)$ increased from 40 to 72 Oe and the residual magnetization $\left(M_{R}\right)$ also increased from $1.75 \times 10^{-3}$ to $7.15 \times 10^{-3} \mathrm{emu} / \mathrm{g}$ by the $\mathrm{N}$ implanta- 


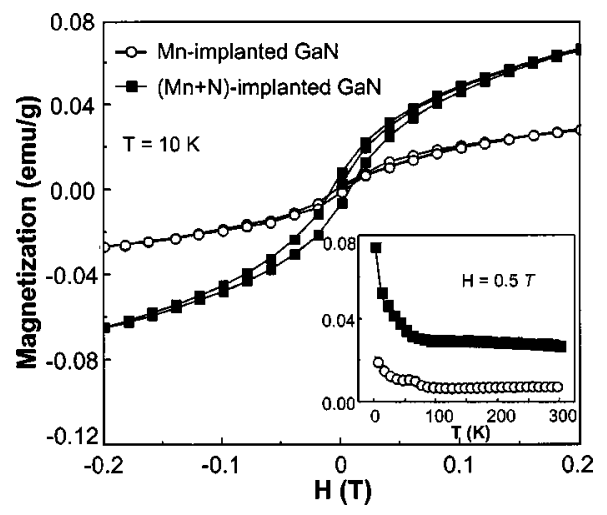

FIG. 1. Magnetization curves of magnetic moment for Mn-implanted and $(\mathrm{Mn}+\mathrm{N})$-implanted samples annealed at $800{ }^{\circ} \mathrm{C}$ for $30 \mathrm{~s}$. The temperature dependence of the magnetic moment is plotted in the inset. The emu/g indicates the magnetization of the entire sample including the substrate.

tion. The temperature dependence of the magnetic moment is plotted in the inset of Fig. 1. The magnetic moment increased after implanting $\mathrm{N}$ ions in the temperature range from $10 \mathrm{~K}$ to $300 \mathrm{~K}$. No superparamagnetic property was observed in the film.

Figures 2(a) and 2(b) show XRD profiles of Mnimplanted and $(\mathrm{Mn}+\mathrm{N})$-implanted samples, respectively. As Mn-implanted samples were annealed at $800^{\circ} \mathrm{C}$, a $\mathrm{Mn}-\mathrm{N}$ compound of $\mathrm{Mn}_{6} \mathrm{~N}_{2.58}$ was produced. When the annealing temperature was increased to $900{ }^{\circ} \mathrm{C}$, the peak intensity of $\mathrm{Mn}_{6} \mathrm{~N}_{2.58}$ increased and a peak corresponding to $\mathrm{Mn}_{3} \mathrm{~N}_{2}$ was observed. On the other hand, no $\mathrm{Mn}_{3} \mathrm{~N}_{2}$ was observed in the $(\mathrm{Mn}+\mathrm{N})$-implanted samples even after annealing at $900{ }^{\circ} \mathrm{C}$. Only a small amount of $\mathrm{Mn}_{6} \mathrm{~N}_{2.58}$ was detected.

Figure 3 displays the SRPES spectra of Mn $2 p_{3 / 2}$ and $\mathrm{Ga} 3 d$ core levels for $\mathrm{Mn}$ - and $(\mathrm{Mn}+\mathrm{N})$-implanted samples with annealing temperature. All samples were in situ etched about $50 \AA$ using Ar-ion sputtering to remove surface oxides. For Mn-implanted GaN, the peak in the Mn $2 p_{3 / 2}$ spectra in Fig. 3(a) corresponds to a $\mathrm{Mn}-\mathrm{N}$ bond considering the XRD data in Fig. 2. When the sample was annealed at $800{ }^{\circ} \mathrm{C}$, a peak [ $\boldsymbol{\nabla}$ in Fig. 3(a)] located at the lower binding energy by about $3.0 \mathrm{eV}$ was found. The change in the height of the peak ( $\mathbf{\nabla})$ in Fig. 3(a) was consistent with the Ga-Mn bond in Fig. 3(b). This suggests that the peak $(\boldsymbol{\nabla})$ in Fig. 3(a)

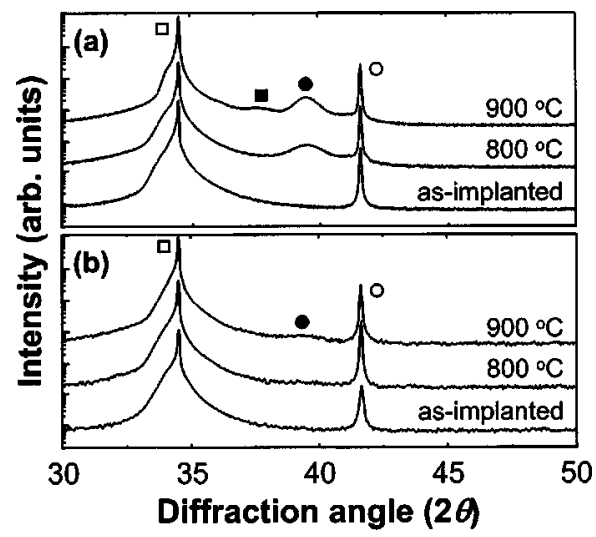

FIG. 2. Change of XRD scans as a function of annealing temperature: (a) Mn-implanted GaN and (b) $(\mathrm{Mn}+\mathrm{N})$-implanted $\mathrm{GaN}$. The incident photon energy of $8 \mathrm{keV}(\lambda=155 \AA)$ was lised in the measurements; ( $\square) \mathrm{GaN}$, (O)

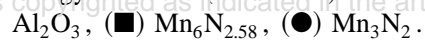

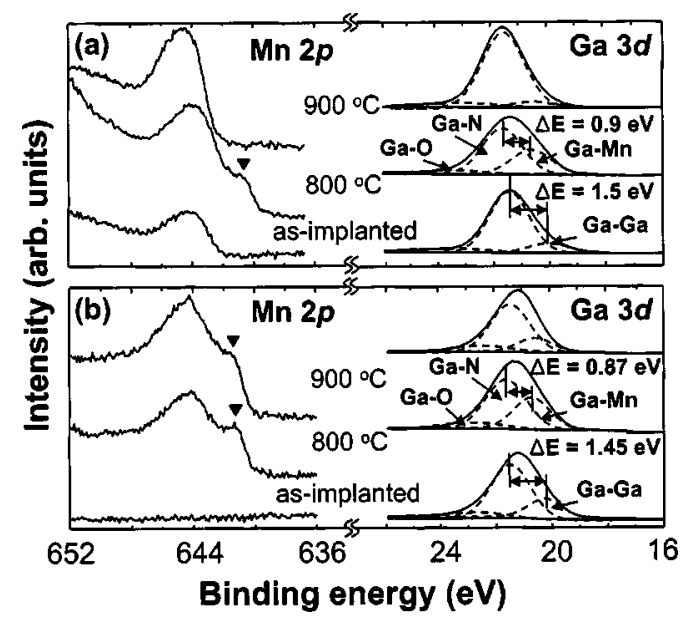

FIG. 3. SRPES spectra of Mn $2 p_{3 / 2}$ and Ga $3 d$ core levels as a function of annealing temperature: (a) Mn-implanted and (b) $(\mathrm{Mn}+\mathrm{N})$-implanted $\mathrm{GaN}$.

corresponds to the $\mathrm{Ga}-\mathrm{Mn}$ bond. The $\mathrm{Ga}-\mathrm{Mn}$ bond in Ga $3 d$ spectra has been described elsewhere. ${ }^{9}$ The peak intensity for the $\mathrm{Ga}-\mathrm{Mn}$ bond increased as $\mathrm{N}$ ions were implanted. Note that the $\mathrm{Ga}-\mathrm{Mn}$ bond disappeared in the $\mathrm{Mn}-$ implanted $\mathrm{GaN}$ after annealing at $900^{\circ} \mathrm{C}$, but was still present in the $(\mathrm{Mn}+\mathrm{N})$-implanted $\mathrm{GaN}$.

The changes of surface band bending of $\mathrm{Mn}$ - and (Mn $+\mathrm{N})$-implanted samples with annealing temperature were observed from the valence-band spectra, as shown in Fig. 4. The Fermi level was determined by linearly extrapolating the sloped region with the base line in the valence-band spectrum of $\mathrm{Au}$ foil, defined as the level of zero-binding energy. After annealing at $800{ }^{\circ} \mathrm{C}$, the Fermi level nearly coincides with the valence-band maximum. This is due to the fact that the surface changed into a metallic surface, consistent with the observation of metallic $\mathrm{Ga}-\mathrm{Mn}$ bonds in Figs. 3(a) and 3(b). When Mn-implanted GaN was annealed at $900{ }^{\circ} \mathrm{C}$, the Fermi level shifted about $0.5 \mathrm{eV}$ toward the conduction band in comparison with the as-implanted sample. This is related to $\mathrm{N}$ vacancies produced during annealing ${ }^{10}$ because $\mathrm{N}$ vacancies act as donors for electrons. ${ }^{11}$ However, no change of the Fermi level with annealing temperature was found in the $(\mathrm{Mn}+\mathrm{N})$-implanted sample, due to the existence of the metallic $\mathrm{Ga}-\mathrm{Mn}$ bond up to $900{ }^{\circ} \mathrm{C}$.

The variations of the $\mathrm{Ga} / \mathrm{N}$ ratio for $\mathrm{Mn}-$ and $(\mathrm{Mn}+\mathrm{N})$ implanted samples with annealing temperature were plotted in Figs. 4(a) and 4(b), respectively. The $\mathrm{Ga} / \mathrm{N}$ ratio was determined from the atomic concentrations of each element,

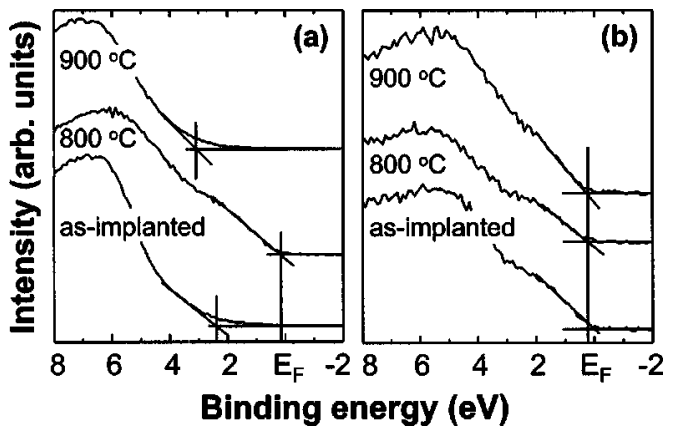

FIG 4. Change of valence-band spectra as a function of annealing temperature: (a) Mn-implanted and (b) $(\mathrm{Mn}+\mathrm{N})$-implanted GaN. 
TABLE I. Resistivity of Mn- and $(\mathrm{Mn}+\mathrm{N})$-implanted samples as a function of annealing temperature.

\begin{tabular}{ccc}
\hline \hline \multirow{2}{*}{$\begin{array}{c}\text { Annealing } \\
\text { temperature } \\
\left({ }^{\circ} \mathrm{C}\right)\end{array}$} & \multicolumn{2}{c}{ Resistivity $(\Omega \mathrm{cm})$} \\
\cline { 2 - 3 } & Mn implanted & $(\mathrm{Mn}+\mathrm{N})$ implanted \\
\hline 700 & 48.11 & 387.90 \\
800 & 8.96 & 755.07 \\
900 & 10.37 & 3814.97 \\
\hline \hline
\end{tabular}

calculated from the integral peak intensities of Ga $3 d$ and $\mathrm{N} 1 s$ spectra. The ratio measured at a detection angle of $\theta=90^{\circ}$ in as-implanted samples was set to 1.0 for reference. In the $\mathrm{Mn}$-implanted $\mathrm{GaN}$, the $\mathrm{Ga} / \mathrm{N}$ increased as annealing temperature increased, indicating the production of a number of $N$ vacancies during annealing. The increase in the $\mathrm{Ga} / \mathrm{N}$ ratio was more pronounced at lower $\theta$. In the meantime, the $\mathrm{Ga} / \mathrm{N}$ ratio decreased with annealing temperature for $(\mathrm{Mn}$ $+\mathrm{N})$-implanted $\mathrm{GaN}$. This means that the surface of the (Mn $+\mathrm{N}$ )-implanted sample maintains a $\mathrm{N}$-rich condition due to $\mathrm{N}$ implantation.

The change of resistivity with annealing temperature is summarized in Table I. Both types of samples are $n$ type, attributed to $\mathrm{N}$ vacancies generated during implantation and annealing. However, it is clear that the resistivity of (Mn $+\mathrm{N}$ )-implanted samples is higher than that of Mn-implanted ones. This may be evidence that production of $\mathrm{N}$ vacancies is suppressed by $\mathrm{N}$ implantation.

When $\mathrm{N}$ ions were implanted in $\mathrm{GaN}$ and annealed, the atomic composition in the implanted region changed to a $\mathrm{N}$-rich condition, viz. a decrease of $\mathrm{N}$ vacancies [Fig. 5]. Mn impurities in $\mathrm{GaN}$ diffused through $\mathrm{N}$ vacancies. ${ }^{8}$ Thus, the Mn diffusion could be suppressed in the $(\mathrm{Mn}+\mathrm{N})$-implanted sample, preventing $\mathrm{Mn}$ atoms from accumulating to form such precipitates, leading to reduction in the amount of $\mathrm{Mn}-\mathrm{N}$ compounds, $\mathrm{Mn}_{3} \mathrm{~N}_{2}$ and $\mathrm{Mn}_{6} \mathrm{~N}_{2.58}$ (Fig. 2). This was evident by the decrease of $\mathrm{Ga} / \mathrm{N}$ ratio in Fig. 5 and the significant increase in resistivity in the $(\mathrm{Mn}+\mathrm{N})$-implanted $\mathrm{GaN}$ in Table I. The $\mathrm{Mn}-\mathrm{N}$ compounds are antiferromagnetic materials with a Néel temperature above $300 \mathrm{~K}$, reducing the

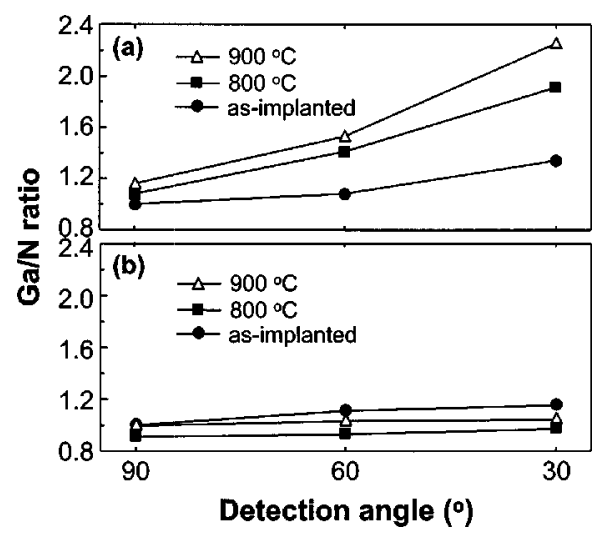

FIG. 5. Change of $\mathrm{Ga} / \mathrm{N}$ atomic ratio with $\mathrm{x}$-ray detection angle as a function of annealing temperature: (a) Mn-implanted and (b) $(\mathrm{Mn}+\mathrm{N})$-implanted $\mathrm{GaN}$. magnetic moment of the Mn-implanted GaN. ${ }^{12,13}$

The enhancement of magnetic properties by $\mathrm{N}$ implantation to Mn-implanted $\mathrm{GaN}$ originated from the $\mathrm{Ga}-\mathrm{Mn}$ bond [Fig. 3(b)], even though such phases were not identified from XRD measurements (Fig. 2). The peak intensity for the $\mathrm{Ga}-\mathrm{Mn}$ bond increased as $\mathrm{N}$ ions were implanted. And the $\mathrm{Ga}-\mathrm{Mn}$ bond was maintained even after annealing at $900^{\circ} \mathrm{C}$. It was reported that the ferromagnetic behavior of Mn-implanted $\mathrm{GaN}$ could be due to the formation of a $\mathrm{Mn}_{3} \mathrm{Ga}$ phase. ${ }^{4}$ Thus, it is suggested that the $\mathrm{Ga}-\mathrm{Mn}$ bond may originate from a binary phase of Ga-Mn. No observation of $\mathrm{Ga}-\mathrm{Mn}$ phases could be attributed to the nanoscale size and the random orientation. The $\mathrm{Ga}-\mathrm{Mn}$ phase could also increase hole concentration due to the formation of $\mathrm{Ga}$ vacancies, which coupled Mn spins randomly distributed in the $\mathrm{GaN}$ film. Consequently, it is proposed that $\mathrm{Ga}-\mathrm{Mn}$ phases play a critical role in enhancing the ferromagnetism in $\mathrm{Mn}$-implanted $\mathrm{GaN}$ and $\mathrm{N}$ implantation to the $\mathrm{Mn}$ implanted $\mathrm{GaN}$ enhances ferromagnetic properties.

In conclusion, the $\mathrm{Ga}-\mathrm{Mn}$ magnetic phases contributing to ferromagnetic properties increased as $\mathrm{N}$ ions were implanted into GaN. Mn-N compounds, such as $\mathrm{Mn}_{6} \mathrm{~N}_{2.58}$ and $\mathrm{Mn}_{3} \mathrm{~N}_{2}$, decreased and resistivity significantly increased, indicating a reduction of $\mathrm{N}$ vacancies in the films. From this, it is suggested that enhancement in ferromagnetic properties by $\mathrm{N}$ implantation originated from the increase of $\mathrm{Ga}-\mathrm{Mn}$ magnetic phases in Mn-implanted GaN.

This work was supported in part by Korea Science and Engineering Foundation through the Quantum-Functional Semiconductor Research Center at Dongguk University in 2003 and in part by the project for "National Research Laboratory" sponsored by the Korea Institute of Science and Technology Evaluation and Planning (KISTEP). Highresolution XRD and SRPES using synchrotron radiation were carried out, respectively, at the 3C2 and 8A1 beamlines at Pohang Accelerator Laboratory (PAL).

${ }^{1}$ H. Ohno, Science 281, 951 (1998)

${ }^{2}$ H. Ohno, A. Shen, F. Matsukura, A. Oiwa, A. Endo, S. Katsumoto, and Y. Iye, Appl. Phys. Lett. 69, 363 (1996).

${ }^{3}$ G. T. Thaler, M. E. Overberg, B. Gila, R. Frazier, C. R. Abernathy, S. J. Pearton, J. S. Lee, S. Y. Lee, Y. D. Park, Z. G. Khim, J. Kim, and F. Ren, Appl. Phys. Lett. 80, 3964 (2002).

${ }^{4}$ N. Theodoropoulou, A. F. Hebard, M. E. Overberg, C. R. Abernathy, S. J. Pearton, S. N. G. Chu, and R. G. Wilson, Appl. Phys. Lett. 78, 3475 (2001).

${ }^{5}$ S. Sonoda, S. Shimizu, T. Sasaki, Y. Yamamoto, and H. Hori, J. Cryst. Growth 237, 1358 (2002).

${ }^{6}$ T. Diel, H. Ohno, F. Matsukura, J. Cibert, and D. Ferrand, Science 287, 1019 (2000)

${ }^{7}$ M. Zajac, J. Gosk, E. Grzanka, M. Kamin'ska, A. Twardowski, B. Strojek, T. Szyszko, and S. Podsiadło, J. Appl. Phys. 93, 4715 (2003).

${ }^{8}$ M. B. Haider, C. L. Constantin, H. Al-Brithen, H. Yang, E. Trifan, D. Ingram, A. R. Smith, C. V. Kelly, and Y. Ijiri, J. Appl. Phys. 93, 5274 (2003).

${ }^{9}$ Y. Nakano and T. Kachi, Appl. Phys. Lett. 79, 1468 (2001).

${ }^{10}$ J. M. Baik, H. W. Jang, J. K. Kim, and J.-L. Lee, Appl. Phys. Lett. 82, 583 (2003).

${ }^{11}$ P. Boguslawski, E. L. Briggs, and J. Bernholc, Phys. Rev. B 51, 17255 (1995).

${ }^{12}$ H. Yang, H. Al-Brithen, E. Trifan, D. C. Ingram, and A. R. Smith, J. Appl. Phys. 91, 1053 (2002).

${ }^{13}$ M. N. Eddine and E. F. Bertaut, Solid State Commun. 23, 147 (1977). 